the bronchi. However, hair follicles were observed in the specimen of this case.

This kind of tumor is usually located in the left upper lobe, as in our case. Because of the presence of thymic tissue in some mediastinal and intrapulmonary teratomas, it has been speculated that these tumors might originate in the thymic tissue. However, the suggestion that early embryogenesis can cause separation or displacement of the thymus can be correct only for tumors found in the anterior mediastinum. The other explanation is that during the initial embryo period, a teratomatous focus in the mediastinum enters that tissue during respiratory growth and settles there. We have not encountered thymic tissue in histologic examinations. ${ }^{2-4}$

Intrapulmonary teratoma is treated by surgical resection. It has been reported that 5 of 18 patients in whom resection was performed died within 1 year. In addition, 4 patients died during the immediate postoperative period. Thus, this kind of tumor causes mortality and morbidity. ${ }^{2,5-7}$ Lobectomy was successful in our case.

\section{References}

1. Schlumberger HG. Teratoma of the anterior mediastinum in a group of military age. Arch Pathol. 1946;41:398.

2. Morgan DE, Sanders C, McElvein RB, et al. Intrapulmonary teratoma: a case report and review of the literature. J Thorac Imaging. 1992;3: 70-7.

3. Ustun MO, Demircan A, Paksoy N, et al. A case of intrapulmonary teratoma presenting with hair expectoration. Thorac Cardiovasc Surg. 1996;44:271-3.

4. Day DW, Taylor SA. An intrapulmonary teratoma associated with thymic tissue. Thorax. 1975;30:582-7.

5. Collier FC, Dowling EA, Plott DBS, Schneider H. Teratoma of the lung. AMA Arch Pathol. 1959;68:138-42.

6. Ali MY, Wong PK. Intrapulmonary teratoma. Thorax. 1964;19:228-35.

7. Trivedi SA, Mehta KN, Nanavaty JM. Teratoma of the lung: report of a case. Br J Dis Chest. 1966;60:156-9.

\title{
Video-assisted thoracoscopic resection for intralobar pulmonary sequestration: Single modality treatment with video-assisted thoracic surgery
}

\author{
James W. Klena, MD, ${ }^{\text {a }}$ Steven J. Danek, MD, FACP, FCCP, ${ }^{\mathrm{b}}$ Todd K. Bostwick, MD, ${ }^{\mathrm{c}}$ \\ Melissa Romero, CNP, and Joel A. Johnson, MD, FACS, ${ }^{a}$ Marquette, Mich
}

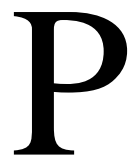

ulmonary sequestration is an uncommon congenital malformation of the foregut. Intralobar sequestrations are delineated by investment of the visceral pleura, lack of communication with the tracheobronchial tree, arterial supply from the aorta, and venous drainage to the left atrium through the pulmonary veins. The lesions usually present with recurrent pneumonia. Traditional management of these lesions has included arteriography to identify the systemic blood supply followed by thoracotomy and lobectomy to resect the sequestration. We report the successful treatment of intralobar pulmonary sequestration with video-assisted thoracoscopic surgery (VATS). VATS allows single modality treatment of intralobar sequestration with reduced morbidity compared with traditional management.

\footnotetext{
From the Departments of Cardiothoracic Surgery, ${ }^{a}$ Pulmonary Medicine, ${ }^{b}$ and Radiology, ${ }^{\mathrm{c}}$ Marquette General Hospital, Marquette, Mich.

Received for publication Dec 14, 2002; accepted for publication Jan 28, 2003.

Address for reprints: James W. Klena, MD, 528 Bishop Woods Road, Marquette, MI 49855 (E-mail: jwklena@yahoo.com).

J Thorac Cardiovasc Surg 2003;126:857-9

Copyright $\odot 2003$ by The American Association for Thoracic Surgery $0022-5223 / 2003 \$ 30.00+0$

doi:10.1016/S0022-5223(03)00364-7
}

\section{Clinical Summary}

A 34-year-old woman, previously in good health, was ad-

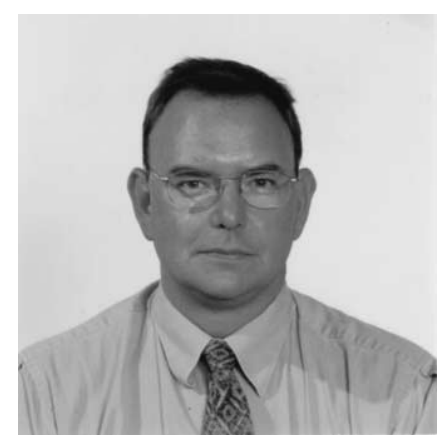

Dr Klena mitted to our institution with a 4-month history of recurrent right lower lobe pneumonia and hemoptysis. The chest $\mathrm{x}$-ray film revealed a persistent consolidation in the right lower lobe despite multiple courses of antimicrobial therapy. Bronchoscopic examination revealed blood in the right lower lobe bronchus but no other abnormalities. Cytology and culture results from the right lower lobe were negative. Spiral computed tomography (CT) of the thorax revealed a mass in the right lower lobe indicating a calcified aberrant blood vessel (Figure 1). The patient was referred to the cardiothoracic surgery service for definitive treatment. A VATS surgical exploration was planned.

The patient was placed in a left lateral decubitus position. A single-lumen endotracheal tube was used with a bronchial blocker placed in the right main-stem bronchus. A 10-mm, 0-degree thoracoscope was used through a port site placed in the seventh intercostal space on the midaxillary line. Two additional port sites were placed in the fifth intercostal space on the anterior and posterior axillary lines, respectively. Port sites were chosen to facilitate the completion of a right lower lobectomy. VATS exploration revealed an aberrant blood vessel emerging from the diaphragm entering the posterior basal segment of the right lower lobe (Figure 2). The affected segment was noted to be consolidated and could be grossly differentiated from the rest of the right lower lobe 


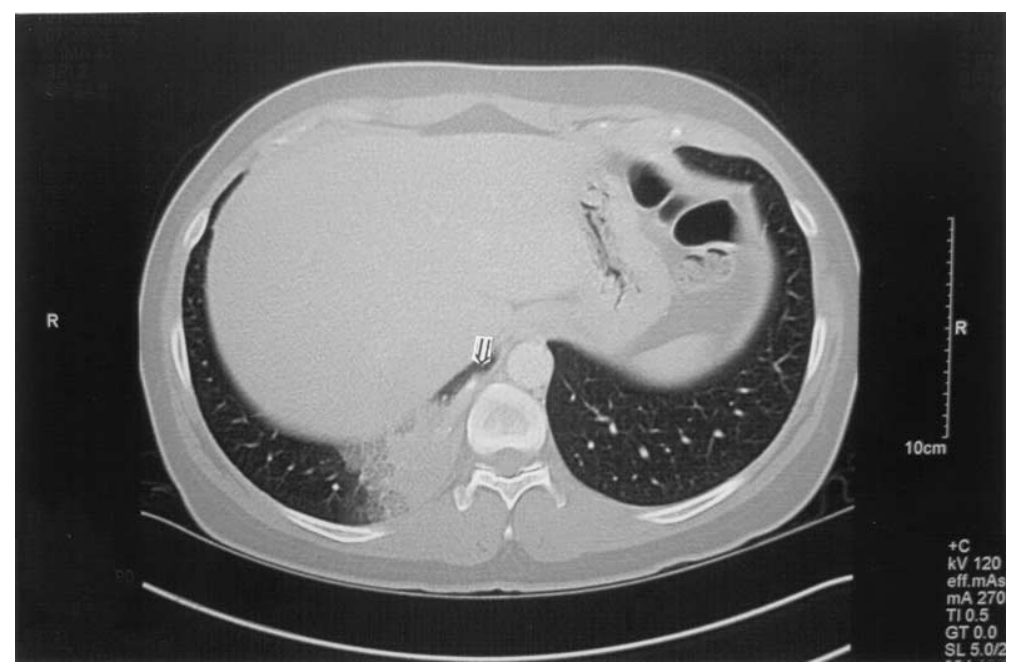

Figure 1. Spiral CT scan of the lower lungs indicating a calcified aberrant feeder artery originating from the descending aorta to the area of right lower lobe consolidation (long arrow).

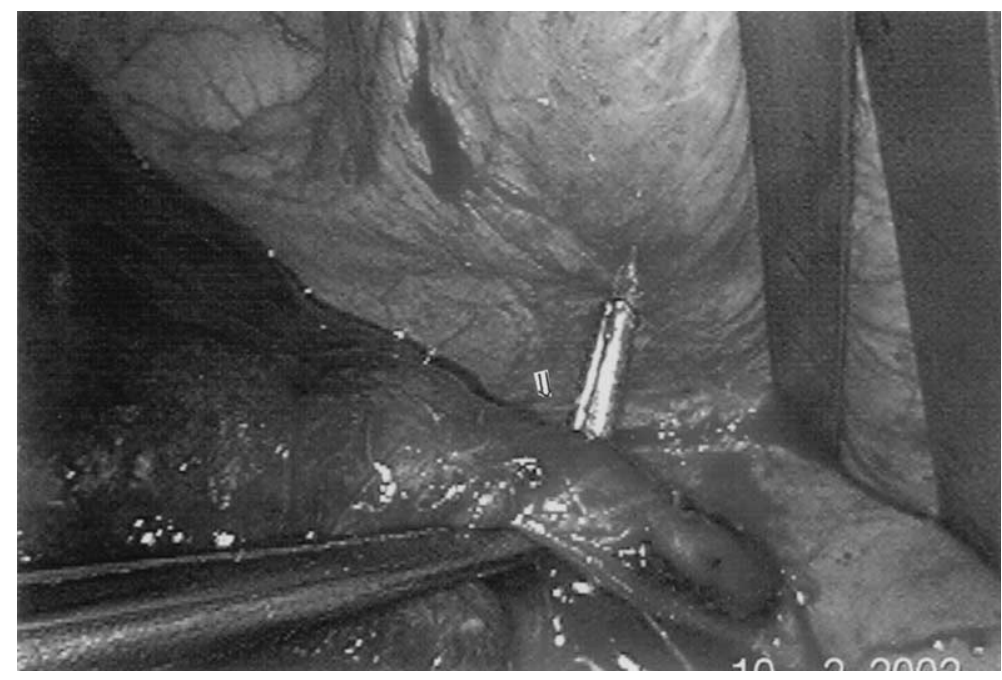

Figure 2. Intraoperative photograph of aberrant feeder artery to right lower lobe sequestration as it emerges from the diaphragm (long arrow).

parenchyma. There was no evidence of other abnormalities of the right lung or pleural space.

The feeding artery from the descending aorta was meticulously dissected from surrounding tissue and divided using a 45-mm articulating endothoracic linear cutting device (Endopath ETS Flex 45, Ethicon, Inc, Cincinnati, Ohio) with 2.5-mm staples. The same device with $3.5-\mathrm{mm}$ staples was used to perform a tailored wedge resection of the right lower lobe removing the sequestration. A single $36 \mathrm{~F}$ chest tube was placed, and the lung was reinflated under direct thoracoscopic visualization. The complement of the right lower lobe appeared anatomically normal after resection of the sequestration.

The patient made an uneventful recovery. Her chest tube was removed on postoperative day 2 , and she was discharged from the hospital on postoperative day 3. Final pathology reports revealed intra-alveolar hemorrhage with abnormal vasculature consistent with intralobar pulmonary sequestration. She remains in good health 3 months after surgery.

\section{Comment}

Pulmonary sequestrations are uncommon congenital malformations of the foregut. There are 2 types: intralobar and extralobar. Intralobar sequestrations are surrounded by visceral pleura, whereas extralobar sequestrations have their own pleura. Both types receive their arterial supply through feeding arteries from the systemic circulation, most commonly the descending aorta. The venous drainage from intralobar sequestrations is through the 
pulmonary venous system, whereas extralobar sequestrations always drain through systemic routes. ${ }^{1}$ Both types of sequestrations are usually asymptomatic, and presentation occurs when they become infected. Diagnosis requires a high index of suspicion. The importance of identifying aberrant blood supply has been advocated to reduce the possibility of serious hemorrhage during resection.

Surgical resection is the definitive treatment for pulmonary sequestration. Preoperative arteriography and open resection have been the recommended approaches for treating the malformation. ${ }^{2}$ Newer radiologic modalities such as spiral CT and magnetic resonance angiography have been used in place of arteriography recently, although open resection through posterolateral thoracotomy is still used. ${ }^{3}$ The ability of VATS to be used as both a diagnostic and therapeutic intervention for numerous thoracic disorders has been described. ${ }^{4}$ VATS lobectomy involving hilar dissection and endovascular division of lobar vessels has been used for non-small-cell lung cancers. In addition, VATS lobectomy for reasons other than malignancy has been advocated because of its reduced postoperative pain and decreased recovery period. ${ }^{5}$

VATS offers the surgeon and patient an alternative method of treatment for intralobar pulmonary sequestration. A presumptive diagnosis can be made from spiral CT. The diagnosis can be confirmed and treated with VATS exploration. Intralobar seques- trations with their venous outflow through the pulmonary veins are ideally suited to VATS resection. If control of the aberrant feeder artery can be obtained with endovascular techniques, a wedge resection of the sequestration or a formal lobectomy can than be performed safely. This method avoids the morbidity of arteriography and thoracotomy for the patient and allows a quicker recovery. Magnetic resonance angiography can also be a useful tool to delineate the vascular anatomy of the sequestration preoperatively.

\section{References}

1. Clements BS, Warner JO. Pulmonary sequestration and related congenital bronchopulmonary malformations: nomenclature and classification based on anatomical and embryologic considerations. Thorax. 1987;42: 401-8.

2. Gustafson RA, Murray GF, Warden HE, Hill RC, Rozar GE. Intralobar sequestration. A missed diagnosis. Ann Thorac Surg. 1989;47:841-7.

3. Halkic N, Cuenoud PF, Corthesy ME, Ksontini R, Boumghar M. Pulmonary sequestration: a review of 26 cases. Eur J Cardiothorac Surg. 1998;14:127-33.

4. Demmy TL. Overview and general considerations for video-assisted thoracic surgery. In: Demmy TL, editor. Video-assisted thoracic surgery (VATS). 1st ed. Georgetown (TX): Landes Bioscience; 2001. pp 1-24.

5. Wan IYP, Lee TW, Sihoe ADL, Ng CSH, Yim APC. Video-assisted thoracic surgery lobectomy for pulmonary sequestration. Ann Thorac Surg. 2002;73:639-40.

\title{
Management of complicated pneumatocele
}

\author{
Paniel J. DiBardino, MD, ${ }^{\text {a }}$ R. Espada, MD, ${ }^{\text {b }}$ P. Seu, MD, and J. A. Goss, MD, ${ }^{a}$ Houston, Tex
}

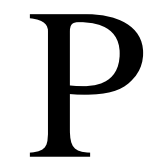
neumatoceles are air-filled lung cysts that occur when bronchial injury or inflammation creates a check-valve mechanism for air entry into the lung parenchyma. Underlying causes include severe pneumonia, blunt thoracic trauma, chronic obstructive pulmonary disease, and hydrocarbon ingestion with aspiration. Seen mostly in children as sequelae of severe pneumonia, most pneumatoceles do not cause serious symptoms and resolve with the treatment of the primary disease process. ${ }^{1}$ Pneumatoceles complicated by rupture, tension, or in-

\footnotetext{
From the Baylor College of Medicine, Michael E. DeBakey Department of Surgery, ${ }^{\mathrm{a}}$ and The Methodist Hospital, Department of Cardiothoracic Surgery, ${ }^{\mathrm{b}}$ Houston, Tex.

Received for publication Jan 9, 2003; accepted for publication Feb 11, 2003.

Address for reprints: Daniel J. DiBardino, MD, 6621 Fannin St, MC WT 19345H, Houston, TX 77030-2399 (E-mail: ab9088@ hotmail.com).

J Thorac Cardiovasc Surg 2003;126:859-61

Copyright $(2003$ by The American Association for Thoracic Surgery $0022-5223 / 2003 \$ 30.00+0$

doi:10.1016/S0022-5223(03)00367-2
}

fection can present dramatically and require urgent treatment. We report the presentation and management of an infected pneumatocele in a 46-year-old woman after orthotopic liver and cadaveric kidney transplantation. On the basis of the available literature and our experience, we suggest that the modern treatment algorithm of complicated pneumatocele begin with percutaneous, image-guided techniques, but we stress that operative intervention be considered early in the face of failed management.

\section{Clinical Summary}

A 46-year-old woman underwent successful orthotopic liver and cadaveric kidney transplantation for polycystic liver and kidney disease. The patient was discharged in excellent condition, and the chest x-ray film before discharge showed normal results. The chest X-ray film on April 1, 2002, revealed a large, thin-walled, air-filled cavity in the right lower lung lobe (Figure 1). The patient remained afebrile and asymptomatic. The chest x-ray film on April 3, 2002, was identical. On April 5, 2002, the patient was admitted to the intensive care unit with the following vital signs: blood pressure $86 / 58 \mathrm{~mm} \mathrm{Hg}$, pulse rate 120 beats/min, respiration rate 40 breaths $/ \mathrm{min}$, temperature $101.9^{\circ} \mathrm{F}$, and oxygen saturation of $96 \%$ on $4 \mathrm{~L}$ nasal cannula. Examination revealed a soft, nontender, and nondistended abdomen; slightly diminished right-sided breath sounds; and a regular heart rhythm with sinus tachycardia. White 